\title{
O SUPREMATISMO NO CONTEXTO DA REVOLUÇÃO CULTURAL BOLCHEVIQUE
}

\section{Patrícia Danza Greco}

Universidade Federal Fluminense - UFF

Pós-Graduação Stricto Sensu - mestrado em História Social

O período de 1917 a 22 caracteriza-se por uma verdadeira convulsão no aparato cultural da Rússia. Em primeiro lugar, o comprometimento da revolução com a alfabetização do povo soviético era evidente, principalmente após a assinatura do decreto Sobre a Mobilização, em 1918, que instituía que todos os cidadãos deveriam aprender a ler e a escrever. Também em 1919, reforçando o anterior, outro decreto foi assinado, denominado A Liquidação do Analfabetismo, que obrigava a alfabetização do povo, com faixa etária entre oito e cinqüenta anos, em língua russa ou em língua materna (e para aqueles que trabalhavam, lhes seriam cedidas duas horas do trabalho sem desconto de salário). Em segundo lugar, todo o sistema oficial de ensino das artes foi transformado, visando atender todos os grupos de artistas, desde o incentivo a correntes mais tradicionalistas até o apoio à arte vanguardista, além de criar meios para levar a arte a uma maior quantidade de pessoas. Através do rádio, por exemplo, a arte passou a atingir um público menos elitista, enquanto que o cinema, bastante estimulado, privilegiou o trabalho coletivo em detrimento do individual.

A partir de outubro de 17, o poder foi organizado através do Conselho dos Comissários do Povo, sob a Presidência de Lenin. Para este, a revolução cultural, após a consolidação dos alicerces políticos, era condição imprescindível para a transformação socialista da Rússia, já que o "nível de cultura capitalista", como previa a teoria revolucionária marxista, era ainda inadequado para a superação do capitalismo. Nas palavras de Trotski ao analisar o pensamento leninista,

a luta pela cultura, dadas as premissas políticas (mas não materiais) 'necessárias e suficientes', ocuparia inteiramente toda a nossa atividade, se não fosse o problema da luta incessante e implacável, no terreno econômico, político, militar e cultural entre a sociedade socialista que se edifica sobre uma base atrasada e o capitalismo mundial $[\ldots]^{1}$.

1 MIRANDA, Orlando (org.). Programa da Revolução Internacional e Programa do Socialismo em um Só País. In: Trotski. São Paulo: Ed. Ática, 1981. p. 205-206. (Coleção Grandes Cientistas Sociais). 
Portanto, em função da sua máxima importância, a revolução cultural deveria respeitar o tempo necessário para adaptação aos novos parâmetros, ao contrário da tomada do poder político que fora fulminante.

Para viabilizar suas idéias, Lenin criou o Comissariado do Povo para a Instrução Pública e delegou sua direção a Anatoli Lunatcharski. Este, além de promover novos tipos de propaganda e decorações de rua, deveria integrar a velha intelectualidade russa à nova realidade vanguardista. Com isto, Lenin não aceitava nem o radicalismo dos que almejavam a implantação de uma imediata cultura proletária, nem a simples aceitação de uma cultura burguesa. Seu intuito era o de conciliar, ainda que temporariamente, ambas as correntes, sendo o mediador o Partido Comunista no poder. Lunatcharki, por sua vez, que era um dos fundadores do Proletkult (programa que incentivava os operários a construírem uma cultura própria), considerava que os jovens artistas, muitos dos quais cubistas e futuristas, estariam mais propensos a aceitar a revolução e, por isto, muitos foram alocados em funções estratégicas, como o caso de Kandinsky (integrante do Narkompros ${ }^{2}$ ) e Malevitch, o qual dirigiu a Escola de Arte de Vitebsk. David Shteremberg, artista plástico, foi o principal consultor artístico de Lunatcharski, além de diretor da IZO, um departamento do Narkompros responsável pelas artes plásticas.

Shteremberg, seguindo os preceitos estabelecidos, sempre trabalhava no sentido de promover a igualdade entre as diferentes tendências artísticas, mantendo as instituições acadêmicas antigas e incentivando a criação e a conservação das obras de arte moderna. Suas atitudes denotavam o tempo todo um grande comprometimento com os ideais igualitários do novo Estado soviético, podendo ser destacada, como exemplo, a eliminação do júri que julgava a entrada de obras de arte no Salão dos Independentes, com o objetivo de tornar a arte livre para qualquer cidadão russo.

Assim, uma cultura modernista acabou se consolidando, em geral de maneira homogênea (não no sentido de um mesmo estilo artístico, mas no sentido do vanguardismo encontrado nos diversos movimentos existentes), coletivista e difundida. Dentre elas, o cinema revolucionário, o teatro político, os grandes projetos urbanísticos modernos e o construtivismo, que influenciou o teatro e as artes gráficas.

2 Agência governamental soviética responsável pela administração da educação e das artes, incluindo a manutenção dos museus e dos monumentos artísticos. 
Tendo isto posto, verifica-se que os artistas soviéticos tiveram um papel muito importante na construção desta nova sociedade, ainda que alguns deles não buscassem propriamente uma conotação política para o seu trabalho (quer dizer, nem todos faziam parte de um partido marxista, mas eram incapazes de praticar sua arte no vazio).

Sem dúvida, Malevitch poderia, em parte, encaixar-se nesta segunda categoria, já que, para ele, o artista deveria ser livre, não podendo sua consciência ser moldada pelo Estado, cuja tentativa seria a de criar uma consciência de massa. Para ele, a realidade conhecida através das coisas se daria de maneira relativa e parcial, sendo necessário tender, como solução, para o conhecimento do mundo como não-objetivo.

Sua poética suprematista preocupava-se em fundir idéia e percepção, transmitindo a supremacia do espírito sobre o objeto (daí sua teorização acerca da não-objetividade do mundo). Assim, suas obras primavam pela pureza das formas e das cores, em composições soltas, libertas de qualquer lei física da gravidade.

O branco no qual flutuam as formas geométricas, embora possa em um primeiro contato transmitir uma sensação de vazio, está, na verdade, repleto da sensação de infinitude do espaço, tanto exterior quanto interior. Além disso, os títulos dos quadros são muito sugestivos, indicando a supremacia da sensibilidade em detrimento da materialidade. Suas telas buscam representar a sensação de determinada ação ou objeto, o conhecimento deste mundo não-objetivo tão buscado por Malevitch.

Além disso, a escolha do quadrado como representação desta fusão entre idéia e percepção não foi aleatória. Este constitui uma forma que não existe na natureza, pois ela é puramente fruto da criação mental. Sendo assim, nenhum outro elemento poderia ser tão apropriado para apresentar o que seria uma arte do mundo das idéias, uma arte que constitui o puro ato de criação; uma arte que é a representação imediata do mundo dos sentimentos. Desta maneira, como bem esclarece Cocchiarale, a essência do Suprematismo e a essência da arte são para Malevitch idênticas - expressão da sensibilidade pura. Dai advém a legitimidade da proposta de uma arte sem representação ${ }^{3}$.

${ }^{3}$ COCCHIARALE, Fernando \& GEIGER, Anna Bella. Abstracionismo Geométrico e Informal; a vanguarda brasileira nos anos 50. Rio de Janeiro: Funarte / Instituto Nacional de Artes Plásticas, 1987. p. 14. 
Em 1918, Malevitch atinge o ápice do suprematismo: Quadrado Branco sobre Branco. Nesta obra, Malevitch, com o branco - que para ele era uma cor mística -, alcança a pura emoção. A harmonia da composição, sem contrastes e, com o quadrado apresentado de maneira inclinada e deslocada, sugere uma ausência total de perspectiva espacial, uma superação das forças de atração da Terra, levando à conquista do todo em estado puro, imaterial. É uma ruptura total com a representação de objetos, apresentando apenas uma única forma que não é vazia, mas repleta da sensação da ausência de objetos.

Nas palavras de Scharf,

...[Malevitch] pretendia transmitir algo como a emancipação final: um estado de nirvana, a afirmação final de consciência suprematista. O quadrado (a vontade humana, talvez o homem?) solta a sua materialidade e funde-se com o infinito. Um tênue vestígio de sua existência é tudo o que resta 4 .

É bem verdade que, como já dito, Malevitch insere-se, em parte, naquela categoria de artistas que não pretendem vincular suas obras a uma ideologia política, nem a uma decadente, nem a uma revolucionária. Todavia, não obstante isto se comprove a um primeiro olhar, é preciso ressaltar que a concepção malevitchiana de um mundo não-objetivo é, sem dúvida, uma concepção proletária, já que implica na não-propriedade de coisas e noções. Numa realidade socialista na qual o indivíduo deve se desapegar dos bens materiais em prol de um coletivo, Malevitch, como indica Argan, surge como um teórico que, embora não faça da sua obra um meio de propagada revolucionária, se ocupa, mediante seu cargo de Professor na Escola de Arte de Vitebsk, da formação intelectual das gerações que irão construir o socialismo ${ }^{5}$.

Ademais, seu contato com El Lissitsky (arquiteto de formação, mas também artista gráfico construtivista) como colega de magistério faz com que Malevitch entusiasme-se com a conquista do espaço pelo suprematismo e comece a trabalhar com projetos arquitetônicos, construídos com gesso e madeira, denominados de Arquitekton.

Com esta idealização, Malevitch expandia o suprematismo para o plano tridimensional, tornando possível a introdução do suprematismo na sociedade, mas não para simples satisfação de necessidades materiais, mas como criação de uma nova estética arquitetônica, cuja essência é a captação

4 SCHARF, Aaron. Suprematismo. In: Conceitos da Arte Moderna. Rio de Janeiro: Jorge Zahar Ed., 2000. p. 101-2.

5 ARGAN, Giulio Carlo. Arte Moderna. São Paulo: Companhia das Letras, 1992. p. 325. 
de um mundo puro, sensível, no qual a arte é compreendida como a síntese da identidade entre um sujeito e um objeto. Em outras palavras, a necessidade material por um determinado objeto foi suplantada pela percepção sensível que o indivíduo tem dele, uma espécie de identidade comum entre ambos.

Como Professor de Vitebsk e membro da IZO, Malevitch pôde, ainda, desenvolver métodos de ensino que, assim como o suprematismo, estavam comprometidos com a liberdade individual de cada artista, tanto perceptiva quanto criativa.

A sala de aula constituía uma espécie de laboratório, no qual o Professor e os alunos, juntos, diagnosticavam as inclinações naturais de cada estudante, elaborando determinadas diretrizes que os auxiliavam a perseguir sua trajetória artística. Além disso, seus "mapas" contendo reproduções de importantes obras do que ele chamava de "a nova arte" estimulavam os alunos a entender como cada estilo possui seu "elemento adicional"', utilizado pelo artista para criar um composto de sensações e conteúdos que clamam pela percepção e intelecto de todo espectador.

Passando agora nas exposições, só é possível compreendê-las tendo em vista tudo o que já foi dito, quer dizer, em que consistia o suprematismo, como ele se estruturava, qual foi o método de ensino desenvolvido por Malevitch... A partir disso, entende-se que os sentidos menores expressos por cada pintura eram sintetizados por um sentido maior na exposição, caracterizada por um todo organizado que permitia a compreensão e a vivência das obras sem o intermédio da palavra.

Para que se torne mais claro, é em função do empenho de Malevitch de construir uma nova arte, pautada numa liberdade individual de percepção de um mundo sensível, que ele também desenvolveu, ao lado de El Lissitsky, uma nova maneira de expor suas obras, um modo revolucionário que contestaria toda a museografia de exposições de arte realizadas até então.

Anteriormente, o espaço expositivo era composto por obras de arte que constituíam entidades independentes, isto é, apresentava uma infinidade de quadros que não dialogavam uns com os outros, pois o ilusionismo gerado pela perspectiva, juntamente com a moldura pesada

6 Os elementos adicionais podem ser a luz (Impressionismo), a superfície modulada ("Cézannismo"), a foice - uma reta seguida por uma curva (Cubismo), o movimento (Futurismo) e a haste diagonal (Suprematismo). 
(redoma), impedia qualquer tipo de contato ou de insinuação de continuidade em relação à tela vizinha.

Malevitch, por sua vez, como já mencionado, afirmava que os estilos artísticos possuíam "elementos adicionais", os quais geram compostos de sensação e conteúdo. Tendo isto em vista, para Malevitch e El Lissitsky, as obras deveriam ser organizadas de maneira que dialogassem entre si, no intuito de que estes compostos fossem sentidos e compreendidos pelo visitante através da relação contínua dos objetos na exposição. Assim sendo, o espectador tornar-se-ia um componente não mais passivo e sim ativo, percebendo, ainda, [...] que ele não é apenas o padrão, o módulo, mas, até certo ponto, o centro da composição ${ }^{7}$.

Corroborando tal pensamento, Deleuze mostra como

[...] os grandes afectos criadores podem se encadear ou derivar, em compostos de sensações que se transformam, vibram, se enlaçam ou se fendem: são estes seres de sensação que dão conta da relação do artista com o público, da relação entre as obras de um mesmo artista ou mesmo de uma eventual afinidade de artistas entre si. ${ }^{8}$

Além disso, outra maneira encontrada de tornar o espectador ativo pode ser evidenciada quando, contratado por Dorner ${ }^{9}$ para projetar a Sala de Arte Construtivista, El Lissitsky desenvolveu um projeto no qual as paredes cinzas eram recobertas por finas ripas pintadas de um lado de branco e do outro de preto. Assim, o espectador ao deslocar-se pela sala ora veria a parede como cinza, ora como branca ou negra, conferindo, com isto, uma tripla vivacidade à exposição. Como bem atentou Bolaños, de este modo se produce una óptica dinámica, asociada al andar humano. Esto obliga al visitante a ser um espectador activo ${ }^{10}$. Além disso, no canto da sala, foram idealizados espaços para pinturas, sobre os quais correria uma tela de aço perfurada que encobriria, em parte, a pintura que estivesse por trás dela. Através disto, o

7 RAKITIN, V. El Lissitzky: 1890-1941. Tradução Pitanga do Amparo. Disponível em <http://worldwhitewall.com/ellissitsky1890-1941.htm>.

8 DELEUZE, Gilles; GUATTARI, Félix. O que é a Filosofia? Rio de Janeiro: Editora 34, 1992. p. 227.

9 Alexander Dorner, Diretor do Landesmuseum de Hannover desde 1922, inaugurou uma nova maneira de organizar suas exposições, ressaltando a importância da historicização dos períodos e das relações entre eles em detrimento do simples destaque a nomes de mestres da pintura e da escultura. Para ele, toda obra não era, apenas, fruto de um gênio individual, mas, sobretudo, expressão da sociedade em que foi produzida.

${ }^{10}$ BOLAÑOS, María. La Memoria del Mundo; cien años de museología 1900-2000. Asturias: Ediciones Trea, 2002. p. 124. Tradução livre: deste modo se produz uma ótica dinâmica associada ao andar humano. Isto obriga o visitante a ser um espectador ativo. 
visitante poderia, ainda, deslizar esta tela de maneira que os quadros que não lhe interessassem naquele momento ficassem subpostos a ela.

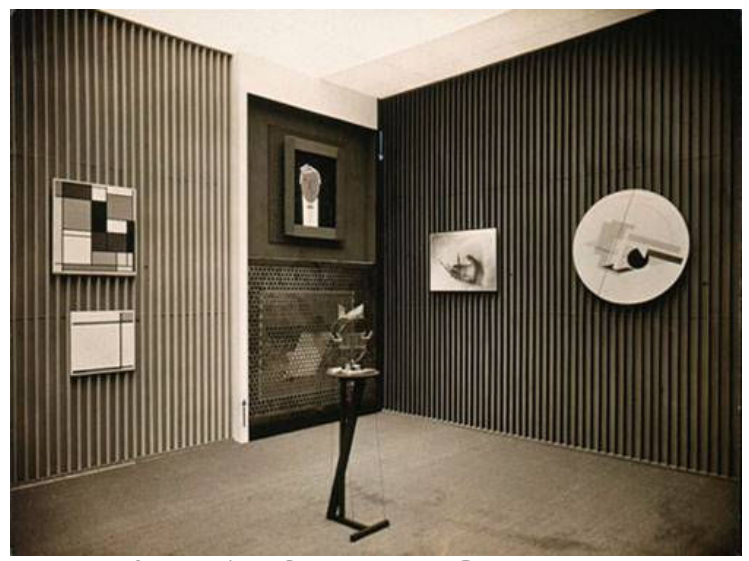

Sala de Arte Construtivista, Dresden, 1926

É de suma importância também enfatizar que, enquanto a parede era aproveitada ao máximo nas grandes exposições dos séculos XVIII e XIX, na Rússia do século XX as obras eram organizadas em composições balanceadas espacialmente, nas quais as partes desse todo harmônico se inter-relacionavam, muito embora em alguns casos as obras mais importantes fossem expostas de maneira a se destacar para o espectador. Tomando como exemplo a Exposição 0.10 ou Última Exposição Futurista, nota-se que a primeira pintura suprematista, O Quadrado Negro, foi colocada por Malevitch no canto da parede, com o intuito de evidenciar a obra mais importante da exposição. Tal atitude tanto gera uma curiosidade no espectador - o qual, por não estar habituado a deparar-se com este tipo de colocação em exposições, percebe fatalmente a presença daquela pintura -, quanto enaltece a nova arte suprematista mistificando-a, já que os ícones (imagens de santos produzidas em placas de madeira com pedras e metais preciosos) típicos da Igreja Ortodoxa eram também pendurados assim nas choupanas camponesas. 


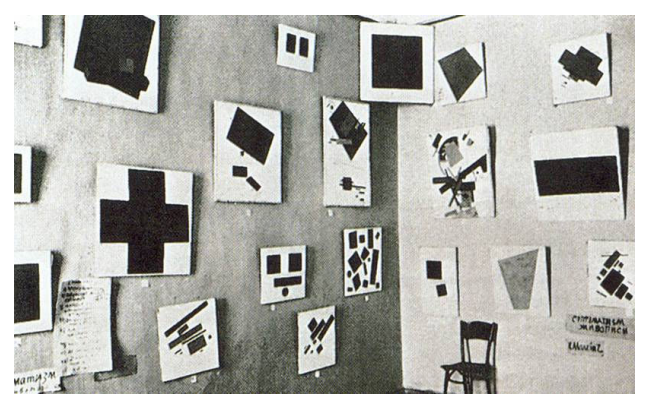

Exposição 0.10,1915

Em suma, as exposições neste período passaram a mediar um processo comunicativo entre a arte e o espectador; uma fórmula para tornar o receptor tão ativo quando o artista que a produziu. Um todo dotado de sentido que clama tanto pela percepção quanto pelo intelecto, para que o posicionamento das obras, junto com a capacidade sensível-intelectual do espectador, produza um verdadeiro diálogo entre elas. Com isto, Malevitch ao lado de El Lissitsky, através de uma nova concepção museográfica, sintetizaria e complementaria o projeto pedagógico e artístico de toda uma vida.

\section{Bibliografia}

ARGAN, Giulio Carlo. Arte Moderna. São Paulo: Companhia das Letras, 1992. 709 p.

BOLAÑOS, María. La Memoria del Mundo; cien años de museología 1900-2000. Asturias: Ediciones Trea, 2002. 395 p.

CANTELE, Bruna Renata. Os Pilares da Educação Coletiva de Makarenko. Disponível em $<$ http:/ / eaprender.ig.com.br/ensinar.asp?RegSel=137\&Pagina=5\#materia $>$.

COCCHIARALE, Fernando \& GEIGER, Anna Bella. Abstracionismo Geométrico e Informal; a vanguarda brasileira nos anos 50. Rio de Janeiro: Funarte / Instituto Nacional de Artes Plásticas, 1987. p. $11-23$.

DELEUZE, Gilles; GUATTARI, Félix. O que é a Filosofia? Rio de Janeiro: Editora 34, 1992.

DRUTT, Mathew (ed.). Kazimir Malevich: suprematism. New York: The Solomon R. Guggenheim Foundation, 2003.

GONÇALVES, Lisbeth Rebollo. Entre Cenografias; o museu e a exposição de arte no século XX. São Paulo: Edusp, 2004.

GOODING, Mel. Arte Abstrata. São Paulo: Cosac \& Naify, 2002. 96 p.

HILTON, Alison. Malevich's Teaching Charts. In: Kasimir Malevich: 1878-1935. Los Angeles: The Armand Hammer Museum of Art and Cultural Center, 1991. Catálogo de Exposição.

LE 20EME SIEClE: L’ESPACE SYMBOLIQUE. La Problematique du Musée. Disponível em $<$ http://mapage.noos.fr/malevich/these002c.html $>$. 
LOPES, João. A Evolução da Política Cultural dos Bolcheviques e a Pintura na União Soviética: Da Liberdade ao Monolitismo do Realismo Socialista [1917-1934]. Disponível em $<$ http://www.pstu.org.br/cont/arte_evolu_cult_bolch.rtf $>$.

MALEVICH, Kasimir. The Non-Objective World; the manifesto of suprematism. New York, Dover Publications, 2003.

MIRANDA, Orlando (org.). Programa da Revolução Internacional e Programa do Socialismo em um Só País. In: Trotski. São Paulo: Ed. Ática, 1981. p. 198-206. (Coleção Grandes Cientistas Sociais).

RAKITIN, V. El Lissitzky: 1890-1941. Tradução Pitanga do Amparo. Disponível em <http://worldwhitewall.com/ellissitsky1890-1941.htm>.

SCHARF, Aaron. Suprematismo. In: Conceitos da Arte Moderna. Rio de Janeiro: Jorge Zahar Ed., 2000. p. 100-2.

WILLETT, John. A Torre de Tatlin. In: HOBSBAWM, Eric (org.). História do Marxismo; o marxismo na época da Terceira Internacional: problemas da cultura e da ideologia. São Paulo: Paz e Terra, 1987. v. 9. 